\title{
Do ICMS ao IVA: a questão das transações interestaduais no Brasil dos anos 90
}

\section{Introdução}

O debate sobre a reforma tributária no Brasil, ao longo dos anos 90, dedicou ao Imposto sobre Circulação de Mercadorias e Serviços (ICMS) grande ênfase. Em primeiro lugar, em razão da importância financeira desse imposto, responsável por enorme parcela dos recursos orçamentários dos Estados e municípios; em segundo lugar, pelo fato de a competência para legislar sobre o ICMS ter ficado com os Estados, em que pesem as restrições impostas pela Constituição e por leis complementares. Essa competência, baseada na Constituição, no entanto, foi exercida paralelamente à edição de leis e decretos sem fundamentação na legislação superior, e esta prática não foi seguida de medidas judiciais restauradoras da ordem jurídica. Como resultado, fortaleceu-se, de fato, o poder dos Estados, e isso vem sendo constatado ao longo das tentativas de transformar o ICMS num imposto mais amplo, com legislação uniforme em todo o País e efetivamente não cumulativo, o chamado "Imposto sobre o Valor Agregado (IVA)".

A peculiaridade do Brasil, em relação aos demais países que utilizam o Imposto sobre o Valor Agregado, desde a implementação do ICM, seu antecessor, nos anos 60, foi atribuir aos Estados a competência para instituir e cobrar esse tipo de imposto. Isso se deve à tradição brasileira de tributação de vendas pelos Estados e ao peso dessa forma de tributação para a receita dessas unidades da Federação.

Como conseqüência, a forma de tributar as transações entre os Estados tornou-se o problema número 1 do ICMS. Em primeiro lugar, devido à disputa pela receita do imposto correspondente aos produtos e

Ivo Vasconcelos Pedrosa é

doutor em

Economia pela

Universidade de

Campinas

(Unicamp), São

Paulo, 1991.

Professor

Titular de

Economia da

Universidade de

Pernambuco

(UPE) e da

Faculdade de

Ciências da

Administração

de Pernambuco

(FCAP).

Contato:

ivovpedrosa@ uol.com.br 
serviços produzidos em um ou vários Estados (várias etapas da cadeia produtiva e distribuição) e consumidos em outros; disputa transformada em "guerra fiscal" pela utilização do imposto como mecanismo de atração de investimentos, que se mostrou apenas redutor da capacidade de investimento dos próprios Estados. Em segundo, em razão dos efeitos econômicos da tributação, uma vez que as alíquotas reduzidas (de 7\% das regiões mais industrializadas para as menos industrializadas) representam maior desvantagem competitiva para as regiões mais pobres (Pedrosa, 1998, p. 259). E, em terceiro, em razão da combinação de dois aspectos relacionados com esse modelo de alíquotas reduzidas: o incentivo à simulação de vendas para fora do Estado, pela aplicação de alíquota inferior, e o traço cultural de impunidade da sonegação, que impede a adoção de medidas contra as práticas de redução do pagamento do imposto.

No início da atual legislatura federal, iniciada em janeiro de 2003 e marcada por momento de grande significação política, em razão da alternância de poder, o debate em torno da transformação do ICMS contemplava duas alternativas principais para o atual modelo de alíquotas reduzidas para tributação das operações interestaduais:

a) a constante da Proposta de Emenda à Constituição aprovada pela Comissão Especial da Câmara dos Deputados em 1999 (PEC 175$\mathrm{B} / 1995)$; e

b) a defendida pelos Estados e incorporada à chamada emenda aglutinativa.

No primeiro caso, a receita do imposto decorrente do consumo seria apropriada pela Unidade Federada de destino, em razão dos seguintes procedimentos:

a) o imposto seria administrado, arrecadado e fiscalizado, de forma compartilhada, pela União, pelos Estados e pelo Distrito Federal;

b) os entes federativos tributariam a mesma base de cálculo, compensando-se separadamente os créditos correspondentes a cada ente; as alíquotas federais seriam estabelecidas por lei federal e as estaduais, pelo Senado;

c) nas operações interestaduais, a alíquota dos Estados seria reduzida a zero e a federal acrescida dos pontos percentuais correspondentes à alíquota do Estado de origem; dessa forma, obter-se-ia a uniformização da tributação, destinando-se a receita à unidade de destino, pois não haveria crédito a ser transferido para o destinatário.

Na proposta defendida pelos Estados, são os seguintes os procedimentos:

a) o imposto seria exigido no Distrito Federal ou no Estado onde ocorresse o fato gerador da operação ou prestação, mediante a aplicação da alíquota uniforme por mercadoria ou serviço; ou seja, o débito do imposto resultaria em arrecadação na unidade de origem, exigindo-se mecanismo para transferência para a unidade de destino; 
b) o produto da arrecadação seria atribuído ao Distrito Federal ou ao Estado de localização do destinatário da mercadoria ou do serviço; a lei complementar poderia instituir fundo, de titularidade e administração conjunta dos Estados e do Distrito Federal, constituído por receitas provenientes da arrecadação do imposto, relativa às operações e prestações interestaduais, para efeito de adoção do princípio de destino.

No modelo aprovado pela comissão da Câmara dos Deputados, a apropriação da receita pela Unidade Federada do consumo é automática. O imposto se torna devido a essa unidade em razão da ausência de crédito nas entradas oriundas de outros Estados.

No caso da proposta dos Estados, no entanto, não está claro o procedimento de definição do montante da receita a ser repassado às unidades de destino. O mecanismo possível é o proposto por Pedrosa (1998, p. 262 et seq.), abrangendo o cálculo de coeficientes aplicáveis sobre a arrecadação de cada Estado ou do Distrito Federal, a serem adotados por todas as unidades federadas, para entrega de parcelas mensais do ICMS às unidades adquirentes de seus produtos e serviços com as quais tivessem saldo de imposto desfavorável. Os coeficientes seriam calculados anualmente com base em informações coletadas, por todos os Estados e pelo Distrito Federal, junto a todos os contribuintes que realizem operações com outras unidades federadas. O tópico seguinte aborda aspectos desse sistema de coleta de informações.

Cumpre ressaltar ser indispensável que o imposto seja exigido na unidade federada de origem. O debate, na mídia, costuma se referir ao princípio de destino com as expressões "cobrança no destino" ou "recolhimento no destino". O fato de o produto da receita vir a pertencer à unidade de destino, onde o consumo, em última instância, se realizar, não deve significar a adoção do destino como local de cobrança, pois isso apenas agravaria as dificuldades atuais, econômicas e de administração fiscal, quando uma parte da receita é deixada para cobrança no destino.

A Proposta de Emenda à Constituição de número 41/2003, encaminhada ao Congresso Nacional pela Presidência da República em 30/04/2003, após acordo com os 27 governadores dos Estados e do Distrito Federal, ao estabelecer a uniformização do imposto, seja em termos de legislação, seja quanto às alíquotas, a serem uniformes por produto ou serviço, abordou necessariamente a questão, mas estabeleceu, de imediato, por exigência dos Estados "perdedores", a manutenção do sistema atual de partilha por dois anos a partir da vigência do novo imposto. Quanto ao procedimento a ser adotado no futuro, sua natureza (constante do inciso VI, do parágrafo $2^{\circ}$ do artigo 155 ) constitui, ainda, motivo de polêmica entre os especialistas, além de depender, conforme o próprio texto da PEC, de definições pela lei complementar que estabelecerá as normas gerais do ICMS. 


\section{A arrecadação do ICMS}

\section{segundo os Estados - 2002}

O ICMS é o principal imposto do País, considerado a arrecadação de todos os Estados e do Distrito Federal. Em 2001, os R 94 bilhões recolhidos representaram $8 \%$ do $\mathrm{PIB}^{1}$. Em 2002, a arrecadação alcançou $\mathrm{R} \$ 104$ bilhões (Tabela 1), total equivalente a 7,9\% do PIB. A Tabela 1 evidencia a concentração da arrecadação no Sudeste (57\%), especificamente em São Paulo, com mais de um terço da receita. Essa concentração é consequiência da característica do imposto, do tipo sobre o valor agregado, refletindo, portanto, a concentração do PIB.

Tabela 1: Brasil - Arrecadação do ICMS segundo as regiões e as principais unidades federadas - 2002 - R\$ milhões

\begin{tabular}{lrc}
\hline UF & Valor - R\$ milhões & \% no total \\
\hline Norte & 5.137 & 4,9 \\
\hline Amazonas & 1.951 & 1,9 \\
\hline Pará & 1.718 & 1,6 \\
\hline Nordeste & 14.494 & 13,9 \\
\hline Pernambuco & 2.811 & 2,7 \\
\hline Bahia & 5.154 & 4,9 \\
\hline Sudeste & 59.589 & 57,1 \\
\hline Minas Gerais & 9.544 & 9,1 \\
\hline Rio de Janeiro & 10.409 & 10,0 \\
\hline São Paulo & 37.254 & 35,7 \\
\hline Sul & 17.087 & 16,4 \\
\hline Paraná & 5.787 & 5,5 \\
\hline Santa Catarina & 3.858 & 3,7 \\
\hline Rio Grande do Sul & 7.441 & 7,1 \\
\hline Centro-Oeste & 8.018 & 7,7 \\
\hline Goiás & 3.020 & 2,9 \\
\hline Brasil & 104.325 & 100,0 \\
\hline
\end{tabular}

Fonte dos dados básicos: Conselho Nacional de Política Fazendária (CoNFAz). Disponível em: www.fazenda.gov.br/confaz. Acesso em 14 mar. 2003.

\section{As estatísticas sobre as transações interestaduais em 1985, 1991 e 1999}

Em meados dos anos 80 havia sido interrompida a produção de 
publicação desse período refere-se ao ano de 1986, mas a relativa a 1985

é considerada de melhor qualidade por conter dados anteriores à reforma monetária do Cruzado, ocorrida no início de 1986.

Em 1992, quando se intensificou o debate em torno da revisão constitucional, prevista na Constituição de 1988, foi desenvolvido algum esforço no sentido de se conhecerem os fluxos interestaduais de mercadorias e serviços. Alguns Estados e a Escola Brasileira de Administração Pública, da Fundação Getúlio Vargas - Rio, a partir de informações que continuavam sendo geradas por algumas unidades da Federação, produziram três estimativas da balança de transações relativa ao ano de 1991²: uma, com base nos valores informados como entradas no estado de destino; outra, com base nos valores informados como saídas no estado de origem; e uma terceira, considerando as entradas da primeira estimativa e as saídas da segunda estimativa.

A terceira das estimativas obtidas para o ano de 1991 apontou a existência de sete Estados superavitários: Amazonas, no Norte; Pernambuco, no Nordeste; Espírito Santo e São Paulo, no Sudeste; e os três Estados do Sul. Com base nessa estimativa, perderiam receita, no caso de mudança do princípio misto para o de destino, os seguintes 11 estados: Amazonas (86,8\%), Ceará (apenas 1\%), Pernambuco (19,3\%), Bahia (apenas 0,2\%), Mato Grosso (17,5\%), Mato Grosso do Sul (10,1\%), Espírito Santo (23,1\%), São Paulo (16,1\%), Paraná (9,2\%), Santa Catarina $(23,3 \%)$ e Rio Grande do Sul (apenas 2,3\%).

Os ganhos de arrecadação, por outro lado, com a mudança do princípio misto para o de destino, em relação à arrecadação de 1991 , ocorreriam em 14 Estados e no Distrito Federal, variando de 1\% em Goiás ${ }^{3}$ a $96 \%$ em Roraima.

Entre 1995 e 1997, em razão do encaminhamento de proposta de reforma tributária ao Congresso Nacional, nova tentativa foi feita, desta vez pelo Ipea, para restabelecer o conhecimento sobre as relações comerciais entre os Estados. No âmbito do Confaz e da Comissão Técnica Permanente do Imposto sobre Operações Relativas à Circulação de Mercadorias e sobre Prestações de Serviços de Transporte Interestadual e Intermunicipal e de Comunicação (COTEPE), foi dado início, nesse período, a uma tentativa de restabelecer a publicação anual das operações interestaduais.

$\mathrm{O}$ atual conhecimento das relações comerciais entre os Estados, seja as relativas a mercadorias, seja a serviços alcançados pela incidência do ICMS, baseia-se no fornecimento, pelos contribuintes desse imposto, de informações anuais acerca das transações por eles efetuadas.

Os Ajustes Sinief (Sistema Nacional Integrado de Informações Econômico-Fiscais) nํำ 1 e no 03/96 (complementar do primeiro), firmados 
pelos Estados e pelo Distrito Federal, constituíram o marco recente de iniciativa do Confaz, visando ao restabelecimento do fluxo de informações sobre a balança de transações entre as unidades federadas, interrompido nos anos de 1980.

Esse esforço recente do Confaz teve origem nos debates em torno da reforma tributária, especialmente com relação ao sistema de repartição de receita do ICMS entre estados "de origem" e "de destino" (ver bibliografia a respeito encontrada em Pedrosa, 1991, 1993 e 1994; Rezende, 1994; e Varsano, 1979, 1987, 1995).

Deve ser lembrado, ao se compararem as posições das unidades federadas nas trocas interestaduais, como é feito nos dois tópicos seguintes, que, entre o ano de 1985 e o de 1999, o ICMS foi ampliado pela Constituição de 1988, passando a incidir sobre minerais, energia, combustíveis e lubrificantes e serviços de transporte interestadual e intermunicipal e de comunicações.

\section{As transações entre Estados, em 1985}

As operações entre as unidades da Federação realizadas nesse ano foram divulgadas pela Secretaria de Economia e Finanças do Ministério da Fazenda, em atendimento ao acordo firmado em 1970, visando à manutenção do Sinief. A Tabela 2 apresenta os saldos ajustados, que resultaram da utilização do maior valor entre os valores informados pelo Estado remetente e pelo Estado destinatário.

Os Estados do Amapá, da Paraíba e de Roraima não forneceram informações, e o Rio de Janeiro somente forneceu as de saídas. Na apuração dos saldos dessas unidades, portanto, o ministério utilizou os dados das demais unidades federadas.

A terceira coluna da Tabela 2 procura aferir a qualidade das informações utilizadas na divulgação. Nesse caso, dispôs-se apenas das operações tributadas. Comparou-se a diferença entre os saldos (o resultante das informações fornecidas pela própria unidade e o decorrente da consideração das informações das demais unidades) e o valor das saídas interestaduais ajustadas. Constata-se grande precariedade das informações, com percentuais maiores que $100 \%$ em Alagoas e Sergipe e com percentuais entre $20 \%$ e $80 \%$ em 11 unidades.

Observa-se que, naquele ano, foram os seguintes Estados superavitários: no Norte, Amazonas; no Sudeste, Minas, Rio de Janeiro e São Paulo; e, no Sul, Paraná e Santa Catarina. 
Tabela 2: Brasil - Saldos das transações interestaduais informadas pelos contribuintes do ICM - 1985 - Cr\$ bilhões

\begin{tabular}{lcc}
\hline Unidade federada & $\begin{array}{l}\text { Saldos ajustados } \\
\text { pelos maiores valores } \\
\text { informados (1) }\end{array}$ & $\begin{array}{l}\text { Diferença entre os } \\
\text { dois saldos como } \% \\
\text { do valor de saídas (1) }\end{array}$ \\
\hline Sergipe & -1.349 & 133,0 \\
\hline Alagoas & -2.711 & 100,8 \\
\hline Pará & -5.142 & 80,4 \\
\hline Rio Grande do Norte & -1.309 & 70,2 \\
\hline Ceará & -4.596 & 54,4 \\
\hline Goiás & -5.847 & 53,8 \\
\hline Acre & -578 & 48,5 \\
\hline Mato Grosso & -4.176 & 46,8 \\
\hline Piauí & -1745 & 44,2 \\
\hline Maranhão & -4.321 & 41,8 \\
\hline Distrito Federal & -7.146 & 37,0 \\
\hline Mato Grosso do Sul & -1.869 & 29,2 \\
\hline Bahia & -1.227 & 25,9 \\
\hline Paraná & 3.465 & 17,0 \\
\hline Rondônia & -1.866 & 15,6 \\
\hline Amazonas & 3.406 & 13,9 \\
\hline Rio Grande do Sul & -279 & 13,7 \\
\hline Pernambuco & -3.415 & 6,3 \\
\hline Espírito Santo & -3.454 & 5,7 \\
\hline São Paulo & 29.765 & \\
\hline Santa Catarina & 1.342 & \\
\hline Minas Gerais & 5.593 & \\
\hline Rio Janeiro (2) & 11.663 & \\
\hline Paraíba (3) & -2.797 & \\
\hline Amapá (3) & -566 & \\
\hline Roraima (3) & -841 & \\
\hline Brasil & 0 & \\
\hline & & \\
\hline
\end{tabular}

Fonte dos dados básicos: Ministério da Fazenda/Secretaria de Economia e Finanças.

(1) Entre o valor de saída informado pelo estado de origem e o valor de entrada informado pelo estado de destino, os responsáveis pela publicação tomaram o maior dos dois valores. A comparação das diferenças entre os saldos foi feita apenas com relação às operações tributadas, pois somente em relação a estas os dois saldos foram divulgados. Considerou-se, apenas, o valor absoluto da diferença entre os saldos.

(2) As informações da própria unidade sobre as entradas não estavam disponíveis.

(3) As informações desses Estados foram prestadas pelos demais Estados; as saídas correspondem às entradas nos demais e as entradas, às saídas. 
As informações sobre a balança comercial interestadual em 1999, divulgadas pela Cotepe, referem-se a 21 Estados e ao Distrito Federal. Cinco Estados não forneceram informações para serem consolidadas: Acre, Amapá, Maranhão, Rio Grande do Norte e Roraima. Note-se que os Estados do Amapá e de Roraima também não haviam fornecido os dados em 1985. A matriz foi complementada, no que se refere aos cinco Estados sem informação, pelas informações das demais unidades federadas: as entradas são as saídas declaradas pelas demais e as saídas, as entradas das demais. Esses cinco Estados responderam por menos de $2 \%$ da arrecadação do ICMS naquele ano. Da mesma forma que, relativamente aos saldos de 1985, foram tomadas as transações totais (tributadas e não-tributadas). As saídas para não-contribuintes (vendas diretas ao consumidor final, via Internet, por exemplo) foram incluídas pela Cotepe nas saídas e nas entradas; nesse caso, a partir das informações de saídas, pois não existe declaração de entradas pelo não-contribuinte.

As chamadas vendas diretas ao consumidor, nas quais se aplica a alíquota interna e funciona o princípio de origem, constitui ponto significativo na discussão da mudança do imposto. Os dados de 1999 revelam um montante dessas transações, informadas pelos Estados de origem, da ordem de $\mathrm{R} \$ 11,2$ bilhões, correspondentes a 3,8\% das operações tributadas totais. São Paulo responde por um quarto dessas saídas e, no caso de aplicação do princípio do destino, sua perda (considerada sua alíquota interna atual de 18\%) seria da ordem de $2 \%$ da arrecadação daquele ano.

Relativamente a 1999, além da ausência de informações prestadas pelos contribuintes dos cinco Estados mencionados, os de Mato Grosso, Mato Grosso do Sul e Rondônia não informaram a quantidade de documentos recebidos. O número de contribuintes dos demais 18 Estados e do Distrito Federal que entregaram a Guia de Informação das Operações Interestaduais (GI) alcançou 985 mil, entre os 3,1 milhões de contribuintes cadastrados.

O Ajuste Sinief no 1/96 autorizou os Estados a dispensarem a apresentação dos documentos em três casos: quando possuírem documentos próprios para a coleta das informações; dos contribuintes classificados como microempresas; e dos produtores agropecuários. É claro que, sendo o objetivo do acordo colher informações sobre transações interestaduais, não é necessário exigir a entrega do documento por contribuintes que somente realizem operações internas, mas os Estados do Rio Grande do Sul e de Santa Catarina exigiram de todos os contribuintes cadastrados. Excetuados esses dois casos, as percentagens de contribuintes cadastrados que entregaram a guia variaram de $7,7 \%$ no Rio de Janeiro e de $13,5 \%$ 
em São Paulo a 56\% no Espírito Santo, sendo de 20,5\% a média nas 17

unidades federadas que informaram o número de declarantes.

A comparação, na Tabela 3, entre os saldos (o resultante das informações fornecidas pela própria unidade e o decorrente da consideração das informações das demais unidades) e o valor das saídas interestaduais demonstra a permanência da grande precariedade das informações, com percentuais maiores que $100 \%$ no Distrito Federal e no Piauí e um número maior de unidades (13), do que em 1985, com percentuais entre $20 \%$ e $75 \%$. No total do país, a divergência entre as informações ultrapassou R\$ 70 bilhões, o equivalente a cerca de 7,2\% do PIB.

Em 1999, além de São Paulo e Amazonas, superavitários em 1985, apresentaram também superávit interestadual o Paraná e o Espírito Santo; mas neste último houve praticamente equilíbrio nas transações de entradas e saídas. O Rio de Janeiro, também superavitário em 1985, apresentou grande saldo deficitário em 1999.

\section{As relações comerciais entre as unidades federadas e a mudança do princípio misto para o princípio de destino}

Neste tópico é feito um exercício com base na matriz obtida com o procedimento mencionado no tópico anterior, no sentido de aferir o impacto, sobre a arrecadação de cada unidade federada, da passagem do princípio misto para o princípio de destino. Discute-se, também, o processo de ajustamento financeiro das unidades federadas durante o período de transição. 
Tabela 3: Brasil - Saldos das transações interestaduais informadas pelos contribuintes do ICMS - operações totais (tributadas e não tributadas) - 1999 - R\$ milhões

\begin{tabular}{|c|c|c|c|}
\hline Unidade federada & $\begin{array}{l}\text { aldos informados } \\
\text { elas unidades }\end{array}$ & $\begin{array}{l}\text { Saldos ajustados } \\
\text { pelos maiores } \\
\text { valores } \\
\text { informados (1) }\end{array}$ & $\begin{array}{l}\text { Diferença entre } \\
\text { os dois } \\
\text { saldos como } \\
\% \text { do valor de } \\
\text { saídas }\end{array}$ \\
\hline Distrito Federal & -1.777 & -7.911 & 267.2 \\
\hline Piauí & -1.007 & -1.954 & 116.4 \\
\hline Rondônia & -411 & -1.329 & 74.5 \\
\hline Pernambuco & -463 & -6.265 & 71.2 \\
\hline Goiás & 36 & -5.116 & 49.0 \\
\hline Alagoas & -753 & -1.507 & 44.0 \\
\hline Mato Grosso & 956 & -1.515 & 33.9 \\
\hline Tocantins & -672 & -935 & 33.6 \\
\hline Rio de Janeiro & 2.721 & -10.136 & 31.6 \\
\hline Ceará & -2.523 & -4.235 & 27.1 \\
\hline Espírito Santo & 3.628 & 47 & 26.5 \\
\hline Bahia & 1.884 & -2.042 & 25.8 \\
\hline Mato Grosso do Sul & -301 & -1.530 & 23.3 \\
\hline Paraíba & -1.565 & -2.135 & 20.8 \\
\hline Pará & -3.952 & -4.473 & 20.7 \\
\hline Minas Gerais & 5.462 & -2.160 & 15.6 \\
\hline Rio Grande do Sul & 1.210 & -2.111 & 11.3 \\
\hline Santa Catarina & -655 & -3.275 & 10.9 \\
\hline Paraná & 8.270 & 5.028 & 8.6 \\
\hline Sergipe & -940 & -1.107 & 7.8 \\
\hline São Paulo & 57.294 & 50.969 & 3.7 \\
\hline Amazonas & 10.659 & 10.266 & 2.4 \\
\hline Amapá (2) & -520 & -520 & 0.0 \\
\hline Maranhão (2) & -3.016 & -3.016 & 0.0 \\
\hline Acre (2) & -489 & -489 & 0.0 \\
\hline Rio Grande do Norte (2) & -2.090 & -2.090 & 0.0 \\
\hline Roraima (2) & -457 & -457 & 0.0 \\
\hline Total Brasil & 70.529 & 0 & 15.5 \\
\hline
\end{tabular}

Fonte dos dados básicos: Confaz/Cotepe - ICMS.

(1) Entre o valor de saída informado pelo Estado de origem e o valor de entrada informado pelo estado de destino, tomou-se o maior dos valores.

(2) As informações desses Estados foram prestadas pelos demais estados; as saídas correspondem às entradas nos demais e as entradas, às saídas. 
É preciso lembrar, de início, que as cargas tributárias setoriais, e até mesmo por produto ou serviço, variam significativamente de Estado para Estado, em razão do uso intensivo do ICMS como instrumento de ampla quantidade de políticas. Assim, o cálculo dos montantes, atual e previsto, de imposto nas operações interestaduais, feito sob hipóteses simplificadas de alíquotas e bases de cálculo, certamente resultou em subestimativa ou superestimativa dos ganhos ou perdas das unidades federadas com as mudanças no imposto.

Deve ser mencionado, ainda, que as atuais alíquotas do imposto são elevadas, entre outras razões, para compensar o estímulo à sonegação representado pela diferença de alíquota nas transações interestaduais, em que se constatam grandes fraudes por meio da indicação de destinatário de outros Estados para operações efetivamente destinadas ao próprio Estado. O Anexo deste trabalho apresenta informações sobre o emblemático caso da fraude ocorrida com o açúcar de São Paulo, destinado, ficticiamente, à Zona Franca de Manaus, para onde o estímulo à sonegação é maior, pois trata-se de isenção, e não apenas de alíquota reduzida.

O exercício, cujos resultados se encontram na Tabela 4, consistiu em aplicar, sobre as saídas e entradas destinadas ou oriundas de cada unidade federada, as alíquotas correspondentes, obtendo-se, por um lado, o imposto atual gerado no Estado de origem e subtraído ao Estado de destino por estas transações, e, por outro lado, o imposto, de igual valor, pertencente ao Estado destinatário na hipótese de adoção do princípio de destino.

Para cada unidade federada foram calculados os ganhos, aplicandose a alíquota interestadual correspondente ( $7 \%$ ou $12 \%$ ) sobre as entradas oriundas das demais unidades, tendo em vista a redução a zero dos créditos atuais, e as perdas, aplicando-se a alíquota correspondente ( $7 \%$ ou $12 \%$ ) sobre os valores de saídas, considerando-se que essas saídas não serão tributadas com a adoção do princípio de destino.

Os seguintes resultados da Tabela 4 podem ser destacados, segundo as regiões:

a) no Norte, um caso à parte é o do Amazonas: o saldo negativo da mudança, se feita de uma única vez, seria equivalente a quase uma vez e meia a arrecadação atual;

b) na mesma Região Norte, os demais Estados além do Amazonas, apresentariam crescimentos na arrecadação que variariam de $20,9 \%$ em Rondônia a 58,9\% no Amapá;

c) no Nordeste, a Bahia seria o único Estado a enfrentar decréscimo de receita, de $13,7 \%$. Os outros oito Estados teriam suas receitas de ICMS aumentadas em percentuais, variando entre 8,3\% no Ceará e 48,9\% no Piauí; 
d) nas Regiões Sudeste e Sul, três Estados teriam perdas com a mudança: o Espírito Santo (40\%), o Paraná (6,6\%) e São Paulo (12\%); os demais Estados dessas duas regiões teriam a receita ampliada entre 11,8\% no Rio Grande do Sul e 26,1\% em Santa Catarina;

e) na Região Centro-Oeste, dois Estados ganhariam (Distrito Federal, 46,7\%, e Tocantins, 30,1\%) e os demais perderiam (de 3,9\% em Goiás a $17,9 \%$ em Mato Grosso).

Deve ser lembrado que os aumentos ou reduções de receita mencionados podem não ocorrer em função da mudança em outros fatores, tais como: alterações no próprio imposto, mudanças na economia (menos prováveis de assumirem proporções elevadas no curto prazo), etc. Calculase o efeito da mudança no princípio de tributação interestadual, considerando-a isolada de outros condicionantes do comportamento da arrecadação.

Oito Estados apresentariam saldos negativos com a mudança, no valor total de $\mathrm{R} \$ 6,2$ bilhões de imposto. Esse total corresponde a 9,1\% da arrecadação do ano de 1999 (R \$ 67,4 bilhões) e indica um montante aproximado que um fundo de compensação das perdas na transição deveria receber anualmente.

Com relação às medidas relacionadas com os impactos das mudanças, deve ser dito que não há razão para se imaginar que essas sejam feitas de uma só vez. É mais que razoável supor que será estabelecido um período de transição (cinco, sete ou dez anos) necessário ao ajuste relacionado com eventual redução dos gastos ou implementação de novas fontes de receita pelas unidades federadas que vierem a apresentar redução de receita. E essa redução, associada à mudança do princípio de tributação - de misto para o de destino -, poderá ocorrer, mas estará acompanhada de muitas compensações, tendo em vista o amplo leque de alterações previstas para o imposto que resultará da reforma (redução do grande número de alíquotas atuais para cinco, variando de Estado para Estado os efeitos positivos ou negativos sobre a arrecadação, a depender de suas alíquotas atuais; restabelecimento dos níveis normais das bases de cálculo, em torno do valor das saídas, atualmente rebaixados por um grande número de convênios firmados no âmbito do Confaz; substituição das isenções por alíquotas muito baixas; etc.). Os ganhos decorrentes da mudança do princípio de tributação, por exemplo, são incomensuráveis, haja vista o estímulo à sonegação atualmente representado pelo princípio misto. Assim, é impossível separar o efeito da implementação do princípio do destino dos relativos a essas outras alterações.

Desse modo, as "perdas" das unidades federadas com superávit atual no balanço de débitos e créditos de imposto nas transações interestaduais não podem, em absoluto, ser examinadas isoladamente, mas em conjunto com os ganhos resultantes das demais mudanças no imposto. 
Uma forma de enfrentar essa questão é considerar o total da arrecadação de cada unidade, após a reforma, confrontando-a com aquela do ano anterior. No período de transição, seria operado um fundo de ajustamento financeiro, por meio do qual seria transferida, em proporção decrescente, ano após ano, parcela do aumento nominal da receita das unidades federadas com ganhos líquidos para as que apresentassem perdas líquidas. Admitindo-se, por exemplo, um período de cinco anos de transição, os percentuais de perdas líquidas compensadas pelo fundo de ajustamento financeiro poderiam ser: $100 \%, 80 \%, 40 \%, 60 \%$ e $20 \%$, ou seja, no primeiro ano da implementação, todas as perdas líquidas seriam cobertas pelo fundo e, a partir do segundo ano, o percentual do montante a ser coberto seria reduzido à base de 20 pontos a cada ano; a extensão do ajustamento de uma unidade poderá ser inferior ao período de transição estabelecido. Os recursos seriam originários das unidades com ganhos líquidos, que contribuiriam para o fundo proporcionalmente ao valor nominal dos aumentos de receita.

Poderia se discutir a necessidade de o valor da arrecadação do ano anterior ser ajustada pela variação anual de um índice geral de preços e do PIB, de modo a, respectivamente, preservar o poder de compra e creditar as unidades por uma contribuição estimada para o produto interno do País.

$\mathrm{O}$ ajustamento financeiro ao longo do período de transição farse-ia seja pela revisão dos programas de gastos, seja implementando novos impostos que viessem a ser autorizados por emenda à Constituição.

Observe-se que essa abordagem dispensa a adoção de alíquotas decrescentes, ao longo de um período de transição, para efeito de tornar a mudança gradual. A alteração pode ser feita de uma só vez, tornando mais simples a adaptação dos contribuintes ao novo imposto.

Verifica-se, portanto, que a questão das "perdas" em razão da mudança do princípio de tributação, no sentido de ser atribuída a receita do imposto ao Estado em que o produto ou serviço é consumido, não pode ser objeto isoladamente de medidas compensatórias, em virtude do grande número de efeitos, positivos e negativos, decorrentes das alterações a serem implementadas no atual ICMS. O que cabe é um processo de ajustamento financeiro do conjunto das unidades federadas ao longo de um período de transição a ser estabelecido.

\section{Considerações finais}

O exame das experiências de levantamento das transações interestaduais mostrou o significado dos esforços feitos por alguns Estados, que mantiveram os seus sistemas de coleta desse tipo de dado em funcionamento, bem como de entidades que desenvolveram estudos sobre eles. 
A importância dessas informações extrapola o âmbito puramente tributário, pois se apresenta como fonte ímpar de conhecimento sobre os movimentos de mercadorias e serviços entre as várias regiões do País.

A estimativa dos efeitos da mudança do princípio misto atual de tributação para o de destino, um dos aspectos das propostas de reforma do Sistema Tributário Nacional em discussão, evidenciou uma transferência de receita da ordem de $\mathrm{R} \$ 6,2$ bilhões de oito Estados para os demais 18 e o Distrito Federal. Esse valor, equivalente a 9,2\% da arrecadação de ICMS em 1999, indica a magnitude anual de recursos a serem alocados a um fundo de ajustamento financeiro, a ser criado, para permitir aos Estados eventualmente perdedores de receita total, durante um período de transição, a ser fixado, a realização de ajuste financeiro. Nesse tempo, eles poderiam reduzir programas de gastos ou implementar novas formas de receita.

Desse modo, após alcançado o estágio do debate em que há grande hegemonia dos grupos defensores de uma legislação nacional do atual ICMS, que leve à uniformização de alíquotas, base de cálculo e procedimentos, cumpre avançar nas medidas a serem adotadas num período de transição após a edição da emenda à Constituição, de lei complementar e demais normas legais. 
Tabela 4: Brasil - Estimativa do impacto da mudança, no ICMS, do princípio misto para o de destino - 1999 - R\$ milhões

\begin{tabular}{lrrrr}
\hline & $\begin{array}{c}\text { Ganhos } \\
\text { alíq. X entr. }\end{array}$ & $\begin{array}{c}\text { Perdas } \\
\text { alíq. X saíd. }\end{array}$ & \multicolumn{1}{c}{ Saldo } & $\begin{array}{c}\text { \% sobre } \\
\text { arrecadação }\end{array}$ \\
\hline Acre & 53.774 & 17.576 & 36.199 & 45,9 \\
\hline Alagoas & 296.868 & 205.837 & 91.031 & 21,7 \\
\hline Amapá & 47.364 & 7.489 & 39.87 & 58,9 \\
\hline Amazonas & 513.416 & 1.994 .966 & -1.481 .551 & $-134,9$ \\
\hline Bahia & 1.415 .755 & 1.827 .870 & -412.115 & $-13,7$ \\
\hline Ceará & 885.311 & 758.804 & 126.507 & 8,3 \\
\hline Distrito Federal & 798.113 & 275.489 & 522.624 & 46,7 \\
\hline Espírito Santo & 1.002 .665 & 1.620 .335 & -617.670 & 40,3 \\
\hline Goiás & 1.190 .975 & 1.262 .105 & -71.130 & $-3,9$ \\
\hline Maranhão & 393.671 & 173.804 & 219.867 & 47,9 \\
\hline Mato Grosso & 682.205 & 874.225 & -192.020 & $-17,9$ \\
\hline Mato Grosso Sul & 509.872 & 634.055 & -124.183 & $-14,5$ \\
\hline Minas Gerais & 6.111 .972 & 5.073 .026 & 1.038 .946 & 16,3 \\
\hline Pará & 581.421 & 301.641 & 279.780 & 31,3 \\
\hline Paraíba & 474.908 & 328.996 & 145.911 & 24,1 \\
\hline Paraná & 4.510 .429 & 4.735 .397 & -224.969 & $-6,6$ \\
\hline Pernambuco & 1.226 .141 & 977.429 & 248.713 & 14,1 \\
\hline Piauí & 264.702 & 97.642 & 167.060 & 48,9 \\
\hline Rio Grande Norte & 389.446 & 246.423 & 143.023 & 23,7 \\
\hline Rio Grande Sul & 3.779 .465 & 3.232 .102 & 547.363 & 11,8 \\
\hline Rio de Janeiro & 6.092 .491 & 4.368 .192 & 1.724 .300 & 23,9 \\
\hline Rondônia & 220.412 & 147.860 & 72.551 & 20,9 \\
\hline Roraima & 50.483 & 12.529 & 37.954 & 58,7 \\
\hline Santa Catarina & 3.278 .258 & 2.687 .679 & 590.579 & 26,1 \\
\hline São Paulo & 14.133 .377 & 17.162 .743 & -3.029 .366 & $-12,0$ \\
\hline Sergipe & 313.025 & 256.827 & 56.198 & 14,3 \\
\hline Tocantins & 158.486 & 93.964 & 64.523 & 30,1 \\
\hline Total Brasil & 49.375 .005 & 49.375 .005 & & \\
\hline & & & & \\
\hline
\end{tabular}

Fonte dos dados básicos: Cotepe/ICMS (www.fazenda.gov.br/confaz). 
1 Ministério da Fazenda. Carga Tributária no Brasil - 2001 (Estudo Tributário 06). Brasília, junho de 2002. 22 p.

2 Ver "Operações Interestaduais Tributadas pelo ICMS no Brasil - 1991". In: Reforma tributária: estudos e propostas (Série Estudos e Pesquisas, no 13, novembro de 1994, do Instituto de Administração Fazendária - IAF Recife, PE). Disponível em: http:// sites.uol.com.br/icpedrosa. Os Estados que dispunham de informações de entradas e saídas, por Estados de origem e destino, eram: Mato Grosso do Sul, Rio Grande do Sul, Santa Catarina e São Paulo.

3 Inclusive Tocantins, porque em 1985, ano em que as informações foram utilizadas na estimativa, esse Estado ainda não havia sido desmembrado de Goiás.

4 Ver Pedrosa, Ivo V. Operações interestaduais com mercadorias e serviços no Brasil1996 (documento elaborado para o IPEA), Recife, agosto de 1998.

5 Conselho de Política Fazendária e seu órgão de assessoramento técnico, a Comissão Técnica Permanente do ICMS, respectivamente.

6 Ver "Balança Comercial Interestadual de 1997, 1998 e 1999". Disponível em: www.fazenda.gov.br/confaz. Acesso em fev. 2003.

7 Ministério da Fazenda. Revista de Finanças Públicas, ano XLVII, no 369, jan-fev-mar de 1987, p. 44-77.

8 Foi dada nova redação ao artigo 81 do Convênio de 15 de dezembro de 1970, que instituiu o Sistema Nacional Integrado de Informações Econômico-Fiscais:

"Artigo 81. As unidades da Federação exigirão dos contribuintes do ICMS a Guia de Informação das Operações e Prestações Interestaduais - GI/ICMS, modelo anexo, destinada a apurar a balança comercial interestadual, que conterá, no mínimo, as seguintes indicações: I - denominação: Guia de Informação das Operações e Prestações Interestaduais GI/ICMS;

II - identificação do contribuinte;

III - inscrição estadual;

IV - período de referência;

V -informações relacionadas com entradas e saídas de mercadorias, aquisições e prestações de serviços, por unidade federada.

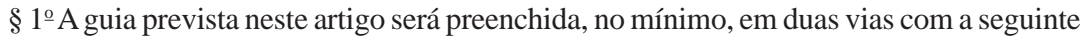
destinação:

a) a $1^{\underline{a}}$ via, para a repartição fiscal competente;

b) a $2^{\mathrm{a}}$ via, ao contribuinte, como prova de entrega ao fisco.

$\S 2^{\circ} \mathrm{A} \mathrm{GI} / \mathrm{ICMS}$ será de periodicidade anual, compreendendo as operações e prestações realizadas no período de $1^{\circ}$ de janeiro a 31 de dezembro de cada exercício, devendo ser entregue pelo contribuinte, conforme a legislação específica de cada unidade federada. $\S 3^{\circ}$ As unidades da Federação poderão dispensar a apresentação da Guia de Informação das Operações e Prestações - GI/ICMS:

1. quando possuírem documentos próprios para coleta dos dados exigidos;

2. de microempresa e produtor agropecuário.

$\S 4^{\circ}$ As unidades da Federação, que incluírem dados relativos a produtor agropecuário e microempresas, deverão informar esses valores em separado."

9 Ver Pedrosa et alii (2000).

${ }^{10}$ Esse foi o procedimento adotado, no início dos anos 90, nas discussões relacionadas com a revisão constitucional. Ver Pedrosa, 1994, p. 97. 


\section{Referências bibliográficas}

Conselho Nacional de Política Fazendária - Confaz. Ajuste SinIEF nº 01/96, de 31.5.96 (Altera o Convênio SINIEF s/nº, de 15.12.70, que instituiu o Sistema Nacional Integrado de Informações Econômico-Fiscais, e o Ajuste SINIEF 04/93, de 9.12.93, que estabelece normas comuns para o cumprimento de obrigações tributárias). In: Diário Oficial da União, no 109, 7.6.96.

- Ajuste Sinief $n^{\circ}$ 3/96, de 13.9.96 (Dispõe sobre a coleta, apuração e consolidação das operações interestaduais no tocante à balança comercial interestadual). Demes, M. Relatório e substitutivo à Proposta de Emenda à Constituição n. ${ }^{\circ}$ 175/95, do Poder Executivo. Altera o capítulo do Sistema Tributário Nacional. Comissão Especial da Reforma Tributária, Brasília, 1998. Mimeografado.

MinISTÉRIO dA FAZENDA. Secretaria de Economia e Finanças. A balança comercial interestadual de 1985. In: Revista de Finanças Públicas, ano XLVII, jan/fev/mar 1987, no 369, p. 44-77, Brasília.

. Carga Tributária no Brasil - 2001 (Estudo Tributário 06). Brasília, junho de 2002. $22 \mathrm{p}$.

Pedrosa, Ivo V. Tributação das operações interestaduais pelo ICMS: uma proposta de mudança. Estudos e Pesquisas, Recife, IAF, n. 2, p. 5-24, out. 1991.

. Tributação do valor agregado no Brasil via ICMS: federalismo e competitividade inter-regional. Estudos e Pesquisas, Recife, IAF, n. 9, p. 38-62, set. 1993. . (Coord.). "Operações interestaduais tributadas pelo ICMS no Brasil 1991". In: Reforma tributária: estudos e propostas (Série Estudos e Pesquisas, n. 13, novembro de 1994, Instituto de Administração Fazendária - IAF.

. Repercussões econômicas da tributação interestadual e alternativas de mudança. In: Revista Econômica do Nordeste, 29:3, p. 255-273, jul./set. 1998.

Pedrosa, Ivo V.; Carvalho, Maria Roseana de; Oliveira, Maria de Fátima C. de A. Renúncia Fiscal do Estado de Pernambuco: estimativa referente ao ICMS de 1996. Revista de Administração Pública, vol. 34(1), p. 229-258, jan./fev. 2000.

Procurador denuncia seis na 'Máfia do Açúcar'. São José do Rio Preto, 26 de agosto de 2001. Disponível em: http://diarioweb.terra.com.br/noticias. Acesso em: 14 abr. 2003.

ReZende, F. A moderna tributação do consumo. In: Mattos Filho, Ary Oswaldo (Coord. Geral). Reforma Fiscal - Coletânea de estudos técnicos. São Paulo, DBA: 1994, v. II.

Usineiros têm fraude bilionária. Jornal do Brasil, Rio de Janeiro, 21 de janeiro de 1994. Disponível em: http://infoener.iee.usp.br/scripts/infoener/hemeroteca. Acesso em: 14 abr. 2003.

VARSANO, R. Os ajustamentos de fronteira do ICM, o comércio interestadual e internacional e a autonomia fiscal dos estados. Pesquisa e Planejamento Econômico, Rio de Janeiro, IPEA, v. 9, n.2, p. 315-350, 1979.

. Tributação de mercadorias e serviços. Rio de Janeiro: IPEA, 1987. Textos para discussão interna, 106. Estudos para reforma tributária, t.3.

. A tributação do comércio interestadual. ICMS atual versus ICMS partilhado. Rio de Janeiro: IPEA/INPES, 1995. Texto para discussão, 382. 


\section{A sonegação baseada em níveis de tributação diferenciados entre os Estados: o caso emblemático da fraude das usinas de São Paulo}

Apresentam-se, a seguir, extratos de duas matérias de jornal sobre as operações fictícias levadas a cabo pelas usinas de São Paulo, envolvendo a Zona Franca de Manaus.

\section{Usineiros têm fraude bilionária}

QuAdros, Vasconcelos - Jornal do Brasil, em 21/1/1994.

A Polícia Federal estima que o volume de dinheiro sonegado pelos usineiros paulistas na fraude do açúcar papel (a venda simulada, acobertada por notas fiscais frias de milhares de toneladas de açúcar para a Amazônia Ocidental) chegue a mais de US\$ 2 bilhões apenas em operações fictícias registradas entre 1992 e 1993. Estão envolvidas, no golpe, 74 das 76 usinas do Estado de São Paulo, 39 delas associadas à Coopersucar, cujo diretor, Sílvio Marinho, irmão do ex-diretor do Departamento de Polícia Federal, Amaury Aparecido Galdino, será indiciado em inquérito policial por sonegação.

Fonte: http://infoener.iee.usp.br/scripts/infoener/hemeroteca

\section{Procurador denuncia seis na "máfia do açúcar"}

São José do Rio Preto, 26 de agosto de 2001.

Júlio Cezar Garcia

O procurador Eleovan César Lima Mascarenhas, do Ministério Público Federal em Rio Preto, ofereceu denúncia contra a 'Máfia do Açúcar', nome pelo qual ficou conhecido um grupo de empresários, corretores e vendedores que negociavam fraudulentamente açúcar na região de Rio Preto. Eles vendiam aqui e emitiam notas fiscais em nome de empresas instaladas na região amazônica, onde o produto goza de isenção fiscal. A denúncia, datada de 17 de agosto último, diz respeito apenas ao inquérito 93.0702477-4.

Os sonegadores retiravam o produto das usinas paulistas, com notas de compra de empresas fantasmas e autenticação falsa na Superintendência da Zona Franca de Manaus (Suframa), o que lhes garantia a isenção. Em vez de seguir para a região incentivada, o açúcar era encaminhado 
à empresa Comércio de Pescados, Alimentos e Bebidas América Ltda., com o nome fantasia de Cristalrio, de Rio Preto, onde era empacotado em embalagens de dois e cinco quilos, para ser vendido a supermercados da região. Agora, após oito anos de investigações, alguns inquéritos entram em fase de conclusão, gerando denúncias dos Ministérios Públicos Federal e Estadual, e processos chegam à fase de sentença.

\section{Histórico}

Segundo a denúncia do procurador federal, o inquérito policial foi instaurado em 16 de junho de 1993 e envolve usinas de açúcar, corretores, empresas fictícias e funcionários da Superintendência da Zona Franca de Manaus (Suframa) lotados em sua sede, em Manaus (AM) e nas representações regionais de Porto Velho e outras localidades. "Na maioria dos casos, a empresa adquirente da mercadoria, embora constasse como instalada na região incentivada, não existia de fato (empresa fantasma). Era constituída, apenas, para o fim específico de figurar como compradora da mercadoria e possibilitar a emissão de notas fiscais pelas usinas sem retenção dos impostos", manifestou o procurador da República.

Para a manobra, os réus utilizavam o sistema PVU (Posto - Venda - Usina), que consistia no recebimento antecipado, pelas usinas, do valor do açúcar adquirido. A usina liberava o produto e a nota fiscal em nome da empresa situada na zona de isenção. A nota deveria ser devolvida à usina autenticada, ou "suframada" como se diz nesse ramo de negócios. A autenticação é também chamada de "filigranação", um expediente que marca em relevo as notas fiscais. Tudo ocorria, segundo o procurador, "através de expedientes fraudulentos".

http://diarioweb.terra.com.br/noticias 
Revista do

Serviço

Público

Ano 54

Número 4

Out-Dez 2003

Ivo Vasconcelos Pedrosa é doutor em

Economia pela Universidade de Campinas

(Unicamp), São Paulo, 1991.

Professor

Titular de

Economia da

Universidade de

Pernambuco

(UPE) e da

Faculdade de

Ciências da

Administração

de Pernambuco

(FCAP).

Contato:

ivovpedrosa@ uol.com.br
Resumo

Resumen

Abstract

\section{Do ICMS ao IVA: a questão das transações interestaduais no Brasil dos anos 90}

Ivo Vasconcelos Pedrosa

O trabalho examina as estatísticas produzidas pelos Estados acerca das transações, submetidas ou não à incidência do ICMS, realizadas entre eles no ano de 1999. Comparamse os resultados com dados anteriores, relativos ao ano de 1985 . O objetivo é compreender o significado dessas transações para a arrecadação do imposto, especialmente no momento em que se avizinha, no âmbito da reforma tributária, a mudança no princípio de tributação, do "misto", preponderante atualmente, para o "de destino". As estatísticas produzidas a partir de 1997, em razão do processo de discussão da reforma tributária, são examinadas sobretudo com vistas à mudança no regime de distribuição da receita entre as unidades federadas. O trabalho indica, sumariamente, as características relacionadas com as transações interestaduais, previstas no debate, para o principal imposto brasileiro - o ICMS.

\section{Del ICMS al IVA: la cuestión de las transaciones interestatales en los años noventa}

Ivo Vasconcelos Pedrosa

El trabajo examina las estadísticas producidas por los estados de la Federación de Brasil respecto a las transaciones, sometidas o no a la incidencia del principal impuesto brasileño, el ICMS, realizadas entre ellos en el año de 1999. Los resultados son comparados con datos anteriores, relativos al año de 1985. El objetivo es comprender el significado de esas transaciones para la recaudación del impuesto, especialmente en el momento en que se aproxima, en el ámbito de la reforma tributaria, el cambio en el principio de tributación, del "mixto", preponderante actualmente, para el de "destino". Las estadísticas producidas, a partir de 1997, en razón del proceso de discusión de la reforma tributaria, son examinadas sobretodo con vistas al cambio en el régimen de distribución de la recaudación entre las unidades federadas. El trabajo indica, someramente, las caracteristicas relacionadas con las transaciones interestatales previstas, en el debate, para el ICMS.

\section{From ICMS to VAT: the interstate transactions issue in Brazil on the nineties Ivo Vasconcelos Pedrosa}

The text examines the statistics produced by Brazilian states concerning the transactions, submitted or not to the incidence of ICMS, the principal Brazilian tax, accomplished among that states in the year of 1999. The results are compared with previous data, relative to the year of 1985 . The objective is to understand the meaning of those transactions for the collection of the tax, especially in face of the imminent tax reform, with the change at the tax principle, from "mixed", the today system, where the preponderant principle is the "origin" principle, for the "destination" one. The produced statistics, starting from 1997 , in reason of the discussion of the tax reform, are examined specially with the focus on the change in the regime of the revenue distribution among the federate units. The work indicates shortly the characteristics, related with the interstate transactions, foreseen in the debate for the ICMS. 